\title{
TESTE DE LIXIVIAÇÃo DE POTÁSSIO PARA AVALIAÇÃo DO VIGOR DE SEMENTES DE SOJA [Glycine max (L.)MERRILL]'
}

\author{
D.C.F.S. DIAS ; J. MARCOS F ${ }^{3}$; Q Q.A.C. CARMELO ${ }^{3}$ \\ ${ }^{2}$ Depto. de Futotecnia - UFV - C.P. 37, CEP: 36570-000 - Vifosa, MG \\ ${ }^{3}$ Depto. de Agricultura - ESALQ/USP - C.P. 9, CEP: 13418-900- Piracicaba, SP \\ ${ }^{3}$ Depto. de Qutmica - ESALQ/USP - C.P. 9, CEP: 13418-900 - Piracicaba, SP
}

RESUMO: O presente trabalho teve como objetivo principal investigar a possibilidade de se obter indicaçбes rápidas sobre a qualidade fisiologica de sementes de soja através do teste de lixiviagăo de potássio, cuja eficiencia foi avaliada comparativamente as informaçzes fornecidas por outros mettodos considerados adequados para a determinação do vigor. Para tanto, utilizon-se quatro lotes de sementes de soja dos cultivares IAC-8 e IAC-15 que foram submetidos aos testes de germinação, primeira contagem de germinação, envelhecimento artificial, condutividade elétrica e determinação do grau de umidade. Além destes foram conduzidos estudos de lixiviação de potássio utilizando-se amostras de sementes não danificadas e de sementes fisicamente puras. A quantidade de potássio lixiviado foi avaliada em fotómetro de chama após $60,90,120$ e 150 minutos de embebiçăo a $30^{\circ} \mathrm{C}$. As avaliaçōes feitas aos 60, 90 e 120 minutos mostraram-se adequadas para a identificação de lotes com diferentes níveis de vigor, constituindo-se em um método simples e rápido para a avaliaçăo da qualidade fisiologica das sementes.

Descritores: soja, sementes, vigor, lixiviação de potássio, Glycine max

\section{POTASSIUM LEACHING TEST FOR THE EVALUATION OF SOYBEAN SEED VIGOUR}

SUMMARY: This work was performed to investigate the possibilities of providing rapid indications on the physiological quality of seeds through the potassium leaching test. Four lots of soybean (Glycine max (L.) Merrill) seeds, cultivars IAC-8 and IAC-15 were submitted to germination, first connt, accelerated aging, electrical conductivity and seed moisture tests. In addition, studies on potassium leaching were conducted with samples of selected non damaged seeds and with pure seeds. The amount of leached potassium was evaluated in a flame photometer after a 60, 90, 120 and 150 minute imbibition at $30^{\circ} \mathrm{C}$. The evaluations after 60,90 and 120 minutes were suitable for the identification of lots with different levels of vigour, thus proving to be a simple and rapid method for seed vigour evaluation.

Key Words: soybean, seeds, vigour, potassium leaching, Glycine max

\section{INTRODUÇÃO}

$\mathrm{Na}$ atualidade, uma das principais exigências em termos de avaliação do vigor de sementes, refere-se à rapidez na obtenção de resultados confiáveis permitindo a agilização das tomadas de decisões, principalmente no que se refere às operaçōes de colheita, processamento e comercialização. De acordo com ABDUL-BAKI \& ANDERSON (1973) testes de vigor que demandam um período de tempo relativamente curto são aqueles relacionados com as atividades enzimáticas e respiratórias e à integridade das membranas celulares, dentre os quais destaca-se o teste de condutividade elétrica que é particularmente interessante para soja (ABDUL-BAKI \& ANDERSON, 1973; YAKLICH et al., 1979;
OLIVEIRA et al., 1984; POWELL, 1986; LOEFFLER et al., 1988 e MARCOS FILHO et al., 1990). Este teste avalia indiretamente a concentração de eletrólitos liberados pelas sementes durante a embebição. Considerando que porção significativa destes eletrólitos e representada por vários fons inorgânicos, alguns estudos têm sido conduzidos visando determinar a liberação de cátions específicos pelas sementes em embebição (ABDEL-SAMAD \& PEARCE, 1978; LOOMIS \& SMITH, 1980; McKERSIE \& STINSON, 1980; MOSS \& MULLET, 1982; SREERAMULU, 1983; GIVELBERG et al., 1984; GRANQVIST, 1987; OLIVEIRA, 1990 e LOTT et al., 1991). Dentre os Íns estudados, o potássio tem merecido especial atenção por se tratar, segundo o exame da literatura,

\footnotetext{
' Parte da tese de doutorado em Fitotecnia da primeira autora, apresentada d ESALQ/USP
} 
do principal íon em termos de quantidade lixiviada podendo ser utilizado como indicador da integridade do sistema de membranas celulares, conforme trabalhos realizados por HALLOIN (1975), McKERSIE \& STINSON (1980); WOODSTOCK et al. (1985) e WEBES \& KARSSEN (1990).

Apesar de pouco estudado, o teste de lixiviação de potássio baseia-se em princípio semelhante ao de condutividade elétrica, com a vantagem adicional de fornecer informações sobre a qualidade fisiologica dos lotes em período de tempo consideravelmente reduzido em relação à condutividade. SIMON \& RAJA-HARUN (1972) e HALLOIN (1975) observaram estreita relação entre os resultados de condutividade elétrica e a quantidade de $\mathrm{K}$ lixiviado em sementes de ervilha e algodão, respectivamente. Por sua vez, WOODSTOCK et al. (1985) concluíram que a quantidade de potássio e cálcio liberados constituíram-se em promissores índices para avaliação do vigor, suplantando a concentração de eletrólitos totais.

Especificamente com relação às sementes de soja, MARCOS FILHO et al. (1982) obtiveram índices de correlação negativos e altamente significativos entre os resultados de lixiviação de potássio e os de germinação, primeira contagem de germinação e envelhecimento artificial; a determinação do potássio liberado pelas sementes foi realizada após 90 minutos de embebição. Constataram, portanto, que este teste de simples execução, forneceu informações suficientes para caracterizar a maturidade fisiológica das sementes.

Diante destas informaçôes, a determinação do potássio lixiviado durante a embebição das sementes pode se constituir em alternativa promissora para a avaliação rápida da qualidade fisiologica das sementes, embora MARCOS FILHO et al. (1984) e BARROS (1988) tenham constatado que o método não foi eficiente para detectar diferenças de qualidade existentes entre os lotes estudados. Contudo, as relações entre quantidade de sementes avaliadas e volume de água para embebição, temperatura e período de condicionamento têm sido variáveis não havendo uma metodologia definida e padronizada. Desta forma, o presente trabalho teve como objetivo principal avaliar a eficiência do teste de lixiviação de potássio comparativamente à outros testes considerados adequados para a determinação do vigor de sementes de soja, procurando-se novos subsídios que permitam indicar a sua utilização em programas de controle de qualidade.

\section{MATERIAL E METODOS}

O trabalho foi conduzido no Laboratório de Sementes da Escola Superior de Agricultura "Luiz de Queiroz"/USP, no período de março a agosto de 1991. Foram utilizadas sementes básicas de soja, dos cultivares IAC-8 e IAC-15, cada um representado por quatro lotes que foram submetidos aos seguintes testes:

Determinação do grau de umidade: efetuada em estufa a $1053^{\circ} \mathrm{C}$ durante 24 horas, utilizando-se duas amostras para cada lote, segundo as prescrições das RAS (BRASIL, 1980), sendo os resultados expressos em porcentagem.

Germinação: foram utilizadas quatro amostras de 50 sementes por lote, semeadas em rolo de papel toalha tipo Germitest, umedecido com quantidade de água equivalente a 2,5 vezes o peso do substrato, e colocadas para germinar à $30^{\circ} \mathrm{C}$. As avaliações foram realizadas aos quatro e sete dias após a semeadura, segundo os critérios estabelecidos pelas RAS (BRASIL, 1980).

Primeira contagem de germinação: conduzida conjuntamente com o teste padrão de germinação, consistindo do registro das porcentagens de plântulas normais encontradas no quarto dia após a semeadura.

Envelhecimento artificial: adotou-se a metodologia recomendada pelo Comitê de Vigor da ASSOCIATION OF OFFICIAL SEED ANALYSTS - AOSA (1983). As sementes foram distribuídas em bandejas de tela de alumínio dentro de caixas plásticas (gerbox) adaptadas funcionando como compartimento individual (mini-câmara) contendo no fundo $40 \mathrm{ml}$ de água; a seguir, as caixas gerbox foram mantidas em incubadora a $41 \pm 0,5^{\circ} \mathrm{C}$ por 48 horas, conforme proposto por KRZYZANOWSKI et al. (1991). Decorrido este período, quatro amostras de 50 sementes por lote foram colocadas para germinar conforme descrito anteriormente. A avaliação foi realizada aos quatro dias após a semeadura, computando-se a porcentagem de plântulas normais.

Condutividade elétrica - CE I: foi adotada a metodologia proposta pelo Comitê de Vigor da AOSA (1983) e descrita por MARCOS FILHO et al. (1987). Quatro repetições de 25 sementes para cada lote, previamente escolhidas para remoção 
daquelas com tegumento danificado, foram pesadas com precisão de $0,01 \mathrm{~g}$ e colocadas em copos plásticos contendo $75 \mathrm{ml}$ de água deionizada. Em seguida, foram levadas para um germinador à $20^{\circ} \mathrm{C}$ por 24 horas. Decorrido esse período, a condutividade elétrica da solução foi determinada através de leitura em condutivímetro Digimed CD20 e os valores médios obtidos para cada lote foram expressos em umhos/cm/g de semente.

Condutividade elétrica - CE II: seguiu-se o procedimento altemativo ao método sugerido pela AOSA (1983) descrito por LOEFFLER et al. (1988). Quatro repetições de 50 sementes, provenientes da porção de sementes. fisicamente puras e pesadas com precisão de $0,01 \mathrm{~g}$ foram colocadas em copos plásticos contendo $75 \mathrm{ml}$ de água destilada; as amostras permaneceram em germinador a $25^{\circ} \mathrm{C}$ por 24 horas. Após este período, a condutividade elétrica das soluções foi determinada conforme descrito no ítem anterior.

Lixiviaçāo de potássio - KI e KII: foi adotada a metodologia desenvolvida por AMORIM (1978) e adaptada por MARCOS FILHO et al. $(1982,1984)$. Foram utilizadas quatro repetições de 25 sementes previamente escolhidas para remoção daquelas danificadas e quatro repetições de 25 , oriundas da porção de sementes puras, pesadas com precisão de $0,01 \mathrm{~g}$. As sementes foram colocadas em copos plásticos contendo $75 \mathrm{ml}$ de água deionizada e mantidas a temperatura de $30^{\circ} \mathrm{C}$, em germinador, por períodos de 60, 90, 120 e 150 minutos. Ap6́s cada período, foram retiradas, de cada amostra, alíquotas de $5 \mathrm{ml}$ para a determinação da quantidade de potássio lixiviado mediante leitura em fotômetro de chama, marca Digimed NK-2004. Os resultados obtidos foram expressos em ppm de potássio/g de semente.

Procedimento estatístico: as análises de variância foram realizadas para cada cultivar e teste conduzido segundo delineamento em blocos ao acaso, com quatro repetições; para o teste de lixiviação de potássio cada período de embebição foi analisado separadamente. A comparação entre as médias foi efetuada através do teste de Tukey ao nível de $5 \%$ de probabilidade.

\section{RESULTADOS E DISCUSSÃo}

Cultivar IAC-8: Analisando os resultados dos testes de lixiviação de potássio (TABELA 1) observou-se que ambas as metodologias (K I e K II) identificaram

TABELA 1 - Lixiviação de potássio (KI e KII): valores (ppm/g) obtidos para os lotes de sementes de soja, cultivar IAC-8, em cada periodo de embebição (média de 3 épocas) e coeficientes de variação. Piracicaba, 1991.

\begin{tabular}{|c|c|c|c|c|c|}
\hline \multirow[t]{2}{*}{ Lotes } & \multicolumn{4}{|c|}{ K I - Períodos (min.) } & \multirow[t]{2}{*}{ Médias } \\
\hline & 60 & 90 & 120 & 150 & \\
\hline$\overline{1}$ & $595 \mathrm{~b}$ & $649 \mathrm{~b}$ & 691 bc & $719 b c$ & 664 \\
\hline 2 & $618 b$ & $679 \mathrm{~b}$ & $726 \mathrm{c}$ & $748 \mathrm{c}$ & 693 \\
\hline 3 & $565 a b$ & $624 \mathrm{~b}$ & $661 \mathrm{~b}$ & $694 \mathrm{~b}$ & 636 \\
\hline 4 & $463 a$ & 491 a & $578 a$ & $613 a$ & 536 \\
\hline Médias & 560 & 611 & 664 & 693 & \\
\hline CV (\%) & 18,46 & 8,66 & 7,27 & 6,64 & \\
\hline \multirow[t]{2}{*}{ Lotes } & \multicolumn{4}{|c|}{ K II - Perfodos (min.) } & Médias \\
\hline & 60 & 90 & 120 & $\overline{150}$ & \\
\hline 1 & $684 \mathrm{bc}$ & $751 \mathrm{~b}$ & $784 \mathrm{~b}$ & $825 \mathrm{~b}$ & 761 \\
\hline 2 & $720 \mathrm{c}$ & $822 b$ & $891 \mathrm{c}$ & $955 \mathrm{c}$ & 847 \\
\hline 3 & $607 \mathrm{ab}$ & $763 \mathrm{~b}$ & 836 bc & $884 b$ & 773 \\
\hline 4 & $554 \mathrm{a}$ & 597 a & $677 \mathrm{a}$ & $729 \mathrm{a}$ & 639 \\
\hline Médias & 641 & 733 & 797 & 848 & \\
\hline CV (\%) & 13,61 & $\mathbf{8 , 8 5}$ & 7,61 & 7,02 & \\
\hline
\end{tabular}

Em cada coluna, médias seguidas pela mesma letra não diferiram entre si, pelo teste de Tukey, em nível de $5 \%$ de probabilidade. 
o lote 4 como superior aos demais, em todos os períodos de embebição estudados. $O$ lote 2 , por sua vez, foi classificado como de pior desempenho na maioria dos estudos, exceto nas avaliações feitas com 90 minutos de embebição, que incluíram nesta categoria também os lotes 1 e 3 . No entanto, os valores absolutos indicam que maior quantidade de potássio foi liberado pelas sementes do lote $2 \mathrm{em}$ relação aos lotes 1 e 3, apesar da análise estatística não ter acusado diferenças significativas entre estes três lotes, após 90 minutos de condicionamento, tanto em KI como em KII.

A semelhança na classificação das médias fornecida pelos dois sistemas $r$. mitiu observar que a remoção de sementes danificadas (KI) não mostrou-se vantajosa, pois além de ser um procedimento subjetivo, requer maior tempo para o preparo das amostras. Portanto, a condução do teste com sementes fisicamente puras revelou sensibilidade para classificar, com rapidez, os lotes em níveis de vigor.

Com referência aos períodos de embebição empregados, notou-se um aumento gradativo da quantidade de putássio lixiviado com o decorrer do tempo, em - nbas as metodologias. Observouse ainda. ; $-\infty$ coeficientes de variação mais altos foram obtidos nas leituras realizadas aos 60 minutos, tanto em KI como em KII. Este fato pode ser atribuído, possivelmente, ao período de condicionamento relativamente curto para a liberação expressiva de íons potássio; assim, a elevada diluição dos exsudatos nesta ocasiāo pode ter contibuído para a variabilidade das leituras como também uma possível variação na velocidade de lixiviação entre repetições, em função, por exemplo, de danos ocorridos nas sementes em diferentes proporções.
Examinando-se a TABELA 2, observa-se que houve uma separação dos lotes em diferentes níveis de qualidade fisiológica. Pelos resultados de germinação, o lote 1 foi superior aos demais embora não tenha diferido estatisticamente do lote 4; em contrapartida, o lote 2 apresentou menor porcentagem de germinação, não diferindo significativamente do lote 3 . O teste de primeira contagem de germinação revelou o melhor desempenho do lote $1 \mathrm{em}$ relação aos lotes 2 e 3 mostrando concordância com os resultados de germinação. Esta semellança pode ser atribuída principalmente, ao fato de que as avaliações foram realizadas com a mesma amostra. Já o teste de envelhecimento artificial apontou o lote 4 como superior, embora não tenha diferido dos lotes 1 e 2 , enquanto o lote 3 exibiu maior sensibilidade às condições de estresse do referido teste. Assim, de modo geral, os dados da TABELA 2 indicaram uma tendência dos testes em destacar os lotes 1 e 4 como superiores; uma separação mais eficiente não foi possível, provavelmente, pelos lotes apresentarem pequenas diferenças de qualidade.

Comparando-se as TABELAS 1 e 2 , verificou-se que o teste de lixiviação de potássio proporcionou informações semelhantes ao teste de envelhecimento artificial, uma vez que ambos indicaram o lote 4 como superior aos demais. No entanto, no que diz respeito a lotes de pior qualidade não houve coerência entre os resultados dos dois testes; neste caso, houve maior semelhança entre os resultados de lixiviação de potássio, germinação e primeira contagem. De fato, a identificação de lotes pode sofrer variações em função da metodologia adotada, principalmente em se tratando de lotes com diferenças de qualidade pouco

TABELA 2 - Valores de germinação, primeira contagem de germinação, envelhecimento artificial, condutividade elétrica (CEI e CEII) e grau de umidade (GU) dos lotes de sementes de soja, cultivar IAC-8 e coeficientes de variação. Piracicaba, 1991.

\begin{tabular}{lcccccc}
\hline \hline LOTES & Germin. & P.Cont. & Env.Artif. & CE I & CE II & GU \\
\hline & $(\%)$ & $(\%)$ & $(\%)$ & umhos/cm/g & umhos/cm/g & $(\%)$ \\
1 & $95 \mathrm{a}$ & $92 \mathrm{a}$ & $85 \mathrm{ab}$ & $63,83 \mathrm{ab}$ & $73,00 \mathrm{ab}$ & 10,6 \\
2 & $91 \mathrm{c}$ & $87 \mathrm{~b}$ & $85 \mathrm{ab}$ & $67,50 \mathrm{~b}$ & $76,99 \mathrm{~b}$ & 11,0 \\
3 & $92 \mathrm{bc}$ & $88 \mathrm{~b}$ & $81 \mathrm{~b}$ & $65,58 \mathrm{~b}$ & $75,72 \mathrm{~b}$ & 10,8 \\
4 & $94 \mathrm{ab}$ & $90 \mathrm{ab}$ & $86 \mathrm{a}$ & $61,66 \mathrm{a}$ & $68,90 \mathrm{a}$ & 10,9 \\
\hline CV (\%) & 4,79 & 4,48 & 4,50 & 6,29 & 5,91 & - \\
\hline
\end{tabular}

Em cada coluna, médias seguidas pela mesma letra não diferiram entre si, pelo teste de Tukey, ao nível de $5 \%$ de probabilidade. 
pronunciadas (KULIK \& YAKLICH, 1982 e MARCOS FILHO et al., 1984). Os resultados indicam ainda, que as avaliações do potássio lixiviado, em todos os períodos de embebição, mostraram a mesma tendência do teste de condutividade de massa (CEI e CEII) ou seja, permitiram a ordenação dos lotes, indicando a superioridade do lote 4 e desempenho inferior para os lotes 2 e 3, contrariando informações obtidas por MARCOS FILHO et al. (1984) e BARROS (1988). Por outro lado, WEBES \& KARSSEN (1990) constataram que a quantidade de potássio lixiviado foi um eficiente indicador da integridade das membranas, sendo portanto, um teste que pode ser considerado promissor para a avaliação do estádio de deterioração das sementes.

Os dados referentes ao grau de umidade das sementes (TABELA 2), embora não tenham sido analisados estatisticamente, foram, de um modo geral, semelhantes para os 4 lotes estudados; este fato é importante na execução dos testes, considerando-se que a uniformização da umidade das sementes é imprescindivel para a padronização das avaliações e obtenção de resultados consistentes (MARCOS FILHO et al., 1987 e LOEFFLER et al., 1988).
Cultivar IAC-15: Os resultados apresentados na TABELA 3 referentes ao teste de lixiviação de potássio indicaram a superioridade do lote 1 tanto na sistema KI como no KII, em todos os períodos de embebição estudados. Pelo método $\mathrm{KI}$, verificouse a possibilidade de classificação dos lotes em níveis de qualidade fisiológica já aos 60 minutos de embebição, com destaque para o melhor desempenho do lote 1 e a qualidade inferior do lote 2 , indicando assim, de acordo com SIMON \& RAJA-HARUN (1972) maior desorganização do sistema de membranas celulares das sementes deste lote. Resultados semelhantes foram obtidos com as avaliações feitas aos 90,120 e 150 minutos indicando que todos os períodos de condicionamento mostraram-se eficientes para a separação dos quatro lotes. Entretanto, o coeficiente de variação de $19,20 \%$ obtido com o período de 60 minutos foi considerado alto, demostrando grande variabilidade nas leituras. Este fato também foi observado para o cultivar IAC-8. No entanto, com 0 decorrer da embebição obteve-se maior uniformidade nas avaliações.

Por outro lado, a condução do teste com sementes fisicamente puras (KII) forneceu informações semelhantes aos 60,90 e 120 minutos

TABELA 3 - Lixiviação de potássio (KJ e KII): valores (ppm/g) obtidos para os lotes de sementes de soja, cultivar IAC-15, em cada período de embebição (média de 3 épocas) e coeficientes de variação. Piracicaba, 1991.

\begin{tabular}{llllll}
\hline \hline \multirow{2}{*}{$\begin{array}{l}\text { Lotes } \\
\text { Médias }\end{array}$} & \multicolumn{5}{c}{ K I - Períodos (min.) } \\
\cline { 2 - 5 } & 60 & 90 & 120 & 150 & \\
\hline $\mathbf{1}$ & $548 \mathrm{a}$ & $642 \mathrm{a}$ & $647 \mathrm{a}$ & $719 \mathrm{a}$ & 639 \\
2 & $879 \mathrm{c}$ & $897 \mathrm{c}$ & $866 \mathrm{c}$ & $913 \mathrm{c}$ & 889 \\
3 & $712 \mathrm{~b}$ & $778 \mathrm{~b}$ & $762 \mathrm{~b}$ & $858 \mathrm{~b}$ & 778 \\
4 & $798 \mathrm{bc}$ & $838 \mathrm{bc}$ & $787 \mathrm{~b}$ & $895 \mathrm{bc}$ & 830 \\
\hline Médias & 734 & 789 & 765 & 846 & \\
CV (\%) & 19,20 & 10,87 & 8,33 & 5,77 & \\
\hline
\end{tabular}

\begin{tabular}{llllll}
\hline Lotes & \multicolumn{5}{c}{ K II - Períodos (min.) } \\
\cline { 2 - 6 } Medias & 60 & 90 & 120 & 150 & 710 \\
\hline 1 & $556 \mathrm{a}$ & $668 \mathrm{a}$ & $737 \mathrm{a}$ & $860 \mathrm{a}$ & 893 \\
2 & $799 \mathrm{~b}$ & $853 \mathrm{~b}$ & $947 \mathrm{~b}$ & $972 \mathrm{~b}$ & 854 \\
3 & $707 \mathrm{~b}$ & $824 \mathrm{~b}$ & $895 \mathrm{~b}$ & $988 \mathrm{~b}$ & 853 \\
4 & $740 \mathrm{~b}$ & $849 \mathrm{~b}$ & $893 \mathrm{~b}$ & $928 \mathrm{ab}$ & \\
Médias & 701 & 804 & 868 & 937 & \\
CV (\%) & 13,91 & 11,08 & 9,47 & 8,24 & \\
\hline \hline
\end{tabular}

Em cada coluna, médias seguidas pela mesma letra não diferiram entre si, pelo teste de Tukey, ao nível de $5 \%$ de probabilidade. 
revelando o melhor potencial do lote $1 \mathrm{em}$ relação aos lotes 2,3 e 4 , os quais não diferiram significativamente entre si. No entanto, a quantidade de potássio lixiviado, em termos absolutos, indica uma tendência de inferioridade para o lote 2. Por sua vez, a avaliação realizada aos 150 minutos de embebição permitiu a ordenação dos lotes, mostrando-se mais sensível, destacando o alto desempenho do lote $1 \mathrm{e}$ a inferioridade dos lotes 2 e 3. Neste caso, o lote 4, classificado nos demais períodos como de qualidade inferior, ocupou posição intermediária (TABELA 3).

A TABELA 3 indica ainda, um aumento na quantidade de potássio lixiviado com o decorrer do tempo, em ambos os sistemas, com leituras mais elevadas para KII o que pode ser atribuído à realização do teste com sementes puras sem eliminar aquelas danificadas; além disso, utilizouse a mesma quantidade de água para a embebição de 50 sementes. Verificou-se, no entanto, que informações mais detalhadas sobre a qualidade fisiológica dos lotes foram obtidas através do sistema $\mathrm{KI}$, ao contrário dos resultados do cultivar IAC-8, onde o método II foi mais eficiente quanto à classificação dos lotes.

E importante salientar que estes resultados indicam que a avaliação da quantidade de potássio presente nos exsudatos das sementes demanda período de tempo relativamente curto, ou seja, inferior a 150 minutos, permitindo que informações sobre a qualidade fisiológica dos lotes sejam obtidas rapidamente. MARCOS FILHO et al. (1982) caracterizaram a maturidade fisiológica de sementes de soja através da lixiviação de potássio. Por outro lado, MARCOS FILHO et al.(1984) e BARROS (1988) não obtiveram resultados promissores com o referido teste em sementes de soja.

Analisando-se os resultados apresentados na TABELA 4, observa-se que, em termos de germinação, o lote 3 mostrou-se superior aos demais, apesar de estatisticamente semelhante ao lote 1 , que não diferiu do lote 4. Este, por sua vez, foi significativamente semelhante ao lote 2 , revelado como de poder germinativo mais baixo. $O$ teste de primeira contagem de germinação identificou o lote 1 como de qualidade fisiológica superior, embora não diferindo estatisticamente do lote 3 , que mostrou-se semelhante aos lotes 2 e 4 , indicados como os de pior desempenho. Já o teste de envelhecimento artificial relacionou os lotes 1 e 3 como superiores aos demais. Por sua vez, os resultados de condutividade (CE I e II) foram semelhantes às informações fornecidas pelos testes de primeira contagem e envelhecimento artificial em termos de separação dos lotes. O método I indicou qualidade supeior $\mathrm{e}$ inferior respectivamente para os lotes 3 e 4 enquanto o sistema 11 (sementes puras) destacou os lotes 1 e 3 em relação aos demais. Portanto, de um modo geral, os testes realizados classificaram os lotes em níveis de qualidade fisiologica, destacando desempenho superior para os lotes 1 e 3 e inferior para os lotes 2 e 4.

Analisando de forma comparativa, observase que os resultados de lixiviação de potássio (TABELA 3) revelaram tendências semelhantes aos testes apresentados na TABELA 4, embora os estudos de potássio tenham indicado a superioridade do lote $1 \mathrm{em}$ relação ao 3, o que não foi detectado pela germinação, primeira contagem, envelhecimento artificial e condutividade CE II. Desse modo, a quantidade de potássio liberado por sementes em embebição mostrou-se sensível quanto à separação de lotes em níveis de vigor, revelando maior precisão.

Destacando as informações obtidas nos estudos de lixiviação de potássio (TABELA 3) e estabelecendo relaçōes com a condutividade elétrica de massa (TABELA 4), verificou-se, de modo geral, concordância quanto à indicação da elevada qualidade do lote 1 , apesar do sistema de massa ter classificado nesta categoria também o lote 3 . Da mesma forma, o teste de condutividade indicou - pior desempenho dos lotes 2 e 4, enquanto o método $\mathrm{KI}$ destacou condição inferior para o lote 2. Estudos realizados por HALLOIN (1975), com sementes de algodão, constataram que a concentração de íons $\mathrm{K}^{+}$mostrou correspondência com a condutividade elétrica dos exsudatos. Também trabalhando com algodão, WOODSTOCK et al. (1985) concluíram que a avaliação da quantidade de $\mathrm{K}^{+}$e Ca ${ }^{++}$liberados pelas sementes embebidas mostrou-se um indicador de qualidade fisiológica mais eficiente do que a quantidade de eletrólitos totais.

Com relação ao grau de umidade das sementes (TABELA 4), apesar de os dados não terem sido analisados estatisticamente, verificouse que, em geral, os valores mostraram-se semelhantes para todos os lotes, conforme observado também para o cultivar IAC-8.

Examinando de uma maneira geral os resultados obtidos verificou-se para o cultivar IAC8 que os testes de germinação, primeira contagem, 
TABELA 4 - Valores de germinação, primeira contagem de germinação, envelhecimento artificial, condutividade elétrica (CEI e CEII) e grau de umidade (GU) dos lotes de sementes de soja, cultivar IAC-15 e coeficientes de variação (medias de 4 Epocas). Piracicaba, 1991.

\begin{tabular}{lcccccc}
\hline LOTES & Germin. & P.Cont. & Env.Artif. & CE & ICE II & GU \\
& $(\%)$ & $(\%)$ & $(\%)$ & umhos/cm/g & umhos/cm/g(\%) & \\
\hline 1 & $90 \mathrm{ab}$ & $88 \mathrm{a}$ & $84 \mathrm{a}$ & $86,62 \mathrm{~b}$ & $95,51 \mathrm{a}$ & 10,8 \\
2 & $87 \mathrm{c}$ & $83 \mathrm{~b}$ & $69 \mathrm{~b}$ & $95,65 \mathrm{~b}$ & $110,49 \mathrm{~b}$ & 10,4 \\
3 & $92 \mathrm{a}$ & $86 \mathrm{ab}$ & $83 \mathrm{a}$ & $77,55 \mathrm{a}$ & $94,50 \mathrm{a}$ & 10,8 \\
4 & $88 \mathrm{bc}$ & $83 \mathrm{~b}$ & $71 \mathrm{~b}$ & $99,59 \mathrm{c}$ & $109,65 \mathrm{~b}$ & 10,5 \\
\hline & & & & & & \\
CV (\%) & 3,91 & 4,43 & 4,08 & 8,22 & 7,40 & - \\
\hline \hline
\end{tabular}

Em cada coluna, médias seguidas pela mesma letra não diferiram entre si, pelo teste de Tukey, ao nível de $5 \%$ de probabilidade

envelhecimento artificial, condutividade elétrica de massa e lixiviação de potássio apresentaram tendências semelhantes na separação dos lotes, embora pequenas variações tenham ocorrido. Tais variações podem ser atribuídas à diferenças de qualidade pouco pronunciadas entre os lotes. Em contrapartida, para o cultivar IAC-15, todos os testes de vigor empregados demonstraram aptidão para separar os lotes em níveis de qualidade fisiológica.

Nos estudos de lixiviação de potássio, resultados consistentes foram obtidos em todos os períodos de condicionamento. Entretanto, cabe ressaltar que com o decorrer do processo de embebição, acréscimos significativos na concentração de potássio dificultaram a realização das leituras diretamente no exsudato sendo necessário, portanto, efetuar diluição. Tal procedimento pode comprometer a precisão das avaliações, além de envolver um maior período de tempo para a obtenção dos resultados, devendo ser, quando possível, evitado. Com base nestas considerações não foi considerada interessante a realização de leituras após 150 minutos de embebição. Assim, ambos os métodos (KI e KII) mostraram-se eficientes, especialmente nas avaliações feitas aos 60,90 e 120 minutos de embebição. Nota-se contudo, que os coeficientes de variação obtidos aos 60 minutos foram considerados relativamente altos.

\section{CONCLUSÕES}

A utilização do teste de lixiviação de potássio permite a identificação de lotes com diferentes níveis de vigor, revelando sua importância para um programa de controle de qualidade mais dinâmico e efetivo.

Para a avaliação da quantidade de potássio lixiviado podem ser considerados como mais adequados o emprego dos períodos de embebição de 60,90 e 120 minutos.

\section{AGRADECIMENTOS}

Os autores agradecem à Fundação de Amparo à Pesquisa do Estado de São Paulo (FAPESP) pelo suporte financeiro.

\section{REFERENCIAS BIBLIOGRAFICAS}

ABDEL SAMAD, I.M. \& PEARCE, R.S. Leaching of ions, organic molecules, and enzymes from seeds of peanut (Arachis hypogaea L.) imbibing without testas or with intact testas. Journal of Experimental Botany, v.29, n.112, p.1471-8, 1978.

ABDUL-BAKI, A.A. \& ANDERSON, J.D. Vigor determination in soybean seed by multiple criteria. Crop Science, v.13, n.6, p.630-3, 1973 .

ASSOCIATION OF OFFICIAL SEED ANALYSTS AOSA. Seed vigor testing handbook. East Lasing: AOSA, 1983. 88p. (AOSA. Contribution, 32).

AMORMM, H.V. Aspectos bioquímicos e histoquímicos do grāo de café verde relacionados com a deterioração da qualidade. Piracicaba, 1978. 85p. Tese (LivreDocência) - Escola Superior de Agricultura "Luiz de Queiroz", Univeraidade de São Paulo.

BRASIL. Ministério da Agricultura. Regras para andise de sementes. Brasflia: SNAD, LANARV, 1980. 188p. 
BARROS, A.S.R. Testes para avaliaçāo rápida da viabilidade e do vigor de sementes de soja (Glycine $\max ($ L.) Merrili). Piracicaba, 1988. 140p. Dissertaçăo (Mestrado) - Escola Superior de Agricultura "Luiz de Queiroz", Universidade de São Paulo.

GIVELBERG,A.;HOROWITZ,M.; POLLJAKOFFMAYER,A. Solute leakage from Solanum nigrum L. seeds exposed to high temperatures during imbibition. Journal of Expimental Botany, v.35, p.161, p.1754 63, 1984.

GRANOVIST, G.A. Leakage of cations from a carrot seed lot. Acta Horticultural, v.215, p.219-24, 1987.

HALLOIN, J.M. Solute loss from deteriorated cottonseed: Relationship between deterioration, seed moisture, and solute loss. Crop Science, v.15, n.1, p.11-5, 1975 .

KRZYZANOWSKI, F.C.; FRANÇA NETO, J.B.; HENNING, A.A. Relato dos testes de vigor disponiveis para as grandes culturas. Informativo ABRATES, v.1, n.2, p.15-37, 1991.

KULIK, M.M.; YAKLICH, R.W. Evaluation for vigor tests in soybean seeds: relationship of accelerated aging, cold, sand bench and speed of germination tests to field performance. Crop Science, v.22, n.4, p.766$70,1982$.

LOEFFLER, T.M.; TEKRONY; D.M.; EGLI, D.B. The bulk conductivity test as an indicator of soybean seed quality. Journal of Seed Technology, v.12, n.1, p.3753,1988 .

LOOMIS, E.L. \& SMTH, O.E. The effect of artificial ageing on the concentration of $\mathrm{Ca}, \mathrm{Mg}, \mathrm{Mn}, \mathrm{K}$, and $\mathrm{Cl}$ in imbibing cabbage seed. Joumal of the American Society Horticultural Science, v.105, n.5, p.647-50, 1980.

LOTT, J.N.A. ; CAVDEK, V.; CARSON, J. Leakage of $\mathrm{K}, \mathrm{Mg}, \mathrm{Cl}, \mathrm{Ca}$ and $\mathrm{Mn}$ from imbibing seeds grains and isolated seed parts. Seed Science Research, v.1, p.229-33, 1991.

MARCOS FILHO, J.; AMORM, H.V.; SILVAROLLA, M.B.; PESCARIN, H.M.C. Relaçoses entre germinaçāo, vigor e permeabilidade das membranas celulares durante a maturação de sementes de soja. In: SEMINARIO NACIONAL DE PESQUISA DE SOJA, 2., Brasília, 1982. Anais. Londrina, EMBRAPA-CNPSo, 1982. p.676-88.

MARCOS FILHO, J.; PESCARIN, H.M.C.; KOMATSU, Y.H.; DEMETRIO, C.G.B.; FANCELLI, A.L. Testes para avaliação do vigor de sementes de soja e sua relação com a emergência das plântulas em campo. Pesquisa Agropecuária Brasileira, v.19, n.5, p.60513,1984

MCKERSIE, B.D.; STINSON, R.H. Effect of dehydration on leakage and membrane structure in Lotus comiculatus L. seeds. Plant Physiology, v.66, n.2, p.316-20, 1980 .
MARCOS FILHO, J.; CICERO, S.M.; SILVA, W.R. Araliecro da qualidade das sementes. Piracicaba, FEALQ, 1987. 230p.

MARCOS FILHO, J.; SILVA, W.R.; NOVEMBRE, A.D.C.L.; CHAMMA, H.M.C.P. Estudo comparativo de métodos para avaliação da qualidade fisiológica de sementes de soja, com ênfase ao teste de condutividade elétrica. Pesquisa Agropecuária Brasileira, v.25, n.12, p.1805-15, 1990.

MOSS, G.I. \& MULLET, J.H. Potassium release and seed vigour in germinating bean (Phaseolus vulgaris L.) seed as influenced by temperature over the previous five generations. Journal of Experimental Botany, v.33, n.137, p.1147-60, 1982.

OLIVEIRA, J. A. Correlaçĩo entre a evolução de hexanal e de aldeidos totais, a lixiviaço de ions e o potencial de germinação de sementes de soja (Glycine max (L.) Merrill). Viçosa, 1990. 79p. Dissertaçāo (Mestrado) - Universidade Federal de Viçosa.

OLIVEIRA, M.A.; MATTHEWS, S.; POWELL, A.A. The role of split seed coats in determining seed vigour to commercial seed lots of soybean, as measured by the electrical conductivity test. Seed Science \& Technologrix.12, n.2, p.659-68, 1984.

POWELL, A.A. Cell membranes and seed leachate conductivity in relation to the quality of seed for sowing. Journal of Seed Technology, v.10, n.2, p.81$100,1986$.

SMON, E.W. \& RAJA-HARUN, R.M. Leakage during seed imbibition. Journal of Experimental Botany, v.23, n.77, p.1076-85, 1972.

SREERAMULU, N. Leakage during imbibition by seeds of bambarra groundnut (Voandzeia subterranea (L.) Thouars) at different stages of 1088 of viability. Tropical Agriculture, v.60, n.4, p.265-68, 1983.

WEBES, R.; KARSSEN, C.M. The influence of redesiccation on dormancy and $\mathrm{K}^{+}$leakage of primed lethuce seeds. Ismel Journal of Botany, v.39, n.4/6, p.327-36, 1990.

WOODSTOCK, L.W; FURMAN, K; LEFFLER, H.R. Relationship between weathering deterioration and germination, respiratory metabolism, and mineral leaching from cottonseeds. Crop Science, v.25, n.3, p.459-66, 1985.

YAKLICH, R.W.; KULIK, M.M.; ANDERSON, J.D. Evaluation of vigor tests in soybean seeds; relationship of ATP, conductivity, and radiontive tracer multiple critera laboratory tests for field performance. Crop Science, v.19, n.6, p.806-10, 1979.

Recebido para publicação em 09.01.95

Aceito para publicação em 26.04 .95 